7. Reprod. Fert. (1970) 23, 11-20

\title{
DEPENDENCE OF PRIMARY AND SECONDARY SEX RATIO ON THE RAPIDITY OF SEDIMENTATION OF BULL SEMEN
}

\author{
MACIEJ KRZANOWSKI
}

Institute of Zootechny, The Gumna Laboratory of Applied Biochemistry of the Experimental Centre of Zootechny, Grodziec Slgski, Poland

(Received 11th August 1969, revised 11th Fanuary 1970)

Summary. Bull semen was separated by sedimentation in milk, with egg-yolk and powdered milk added. The sex ratio (SR) of the progeny of 2866 cows inseminated with sedimented spermatozoa was compared to that of 2171 cows inseminated with unsedimented semen from the same sires. After insemination with the more rapidly sedimenting spermatozoa, a statistically significant preponderance of females was born compared to the number born after insemination with the remaining fractions of the sedimented semen. The percentage of males born after insemination with the slower sedimenting spermatozoa, however, was not higher than that in the control series. After insemination of sedimented semen, there was an increase in abortion and a deviation of the SR to the disadvantage of the numbers of males born, probably due to a more frequent abortion of male foetuses. The differentiation in the SR of the progeny, depending on the fraction used for insemination, remained, even allowing for correction as to the supposed sex of the aborted foetuses.

It is suggested that the more rapid sedimentation of spermatozoa with an $\mathrm{X}$ chromosome was caused by their greater ability to agglomerate.

\section{INTRODUGTION}

In the last decade, there have been several reports on the possibility of sex regulation in progeny by insemination with semen differentiated by free sedimentation into fractions rich in spermatozoa containing either an $\mathrm{X}$ chromosome, sedimenting at a faster rate, or a $\mathrm{Y}$ chromosome, sedimenting at a slower rate. These experiments were based on the assumption that spermatozoa with an $\mathrm{X}$ chromosome were heavier.

Bhattacharya $(1958,1962)$ was the first to obtain $75 \%$ of females in a litter of rabbits inseminated with fractions sedimenting at a faster rate and $80 \%$ of males in a litter of those inseminated with fractions sedimenting at a slower rate. His experiment was based on a small sample and the percentage of males and females was calculated from the total number of animals born, as well as of foetuses extracted by operation, which diminished the value of the experiment. 
Andersen \& Rottensten (1962), in a similar experiment, obtained a slight preponderance of females from all the inseminated spermatozoa, regardless of their rate of sedimentation. Nevertheless, Bhattacharya's report incited other investigators to check the value of the method.

Similar experiments were carried out on cattle by Schilling $(1965,1966)$. He used a different medium, which permitted shortening the time of sedimentation from $12 \mathrm{hr}$ to $60 \mathrm{~min}$, and only published the results of inseminations with fractions sedimenting at a faster rate. In a progeny of eighty-six individuals, he obtained $70 \%$ of females which confirmed the hypothesis.

Investigations by Bhattacharya, Bangham, Cro \& Keynes (1966) on cattle by Bhattacharya's method, as well as those by Bedford \& Bibeau (1967) on rabbits by Schilling's method, found no deviation of sex ratio (SR) in the progeny. All the cited works were based on a small sample, i.e. a progeny of not more than 100 individuals. The usefulness of this method of sex regulation seems to be proved best by the investigation of Knaack (1968), carried out on a great number of cattle. Among 707 calves born, there were $63.2 \%$ of females after insemination with spermatozoa sedimenting at the fastest rate and $61.9 \%$ of males after insemination with the two last fractions.

All the above investigators allowed the semen to separate for 1 to $12 \mathrm{hr}$ at a temperature approximating to $0^{\circ} \mathrm{C}$ in a medium of milk, egg-yolk, glycerine, gelatin and antibiotics. Menger \& Knaack (1967) emphasized the importance of temperature and affirmed that separation is satisfactory if the temperature does not exceed $0^{\circ} \mathrm{C}$.

The authors of the above works did not take into account the individual predisposition of the sires to beget a progeny of an individual SR and did not investigate whether that SR could be changed by the method used. Neither did they investigate whether the method influenced the primary SR, nor if it implied an increase in the absolute number of individuals born of the desired sex.

The aim of this work is to answer those questions.

\section{MATERIALS AND METHODS}

The semen was collected from seventeen bulls and processed at the laboratory of the Animal Insemination Centre at Drogomysl.

The semen was allowed to separate in cooled burettes (with an internal diameter of $1 \mathrm{~cm}$ ) at $2^{\circ}$ to $4^{\circ} \mathrm{C}$ for 1 to $5 \mathrm{hr}$ in a medium of:

(a) skimmed milk enriched with powdered skimmed milk (1 to $4 \%$ ) and egg-yolk ( 0 to $5 \%$ ). This medium was used in two-thirds of the fractionations.

(b) skimmed milk enriched with egg-yolk (6 to $11 \%$ ).

(c) whole milk enriched with egg-yolk (0 to $10 \%$ ).

The density $\left(\mathrm{d}_{20}{ }^{\circ} \mathrm{C}\right)$ of the media used was 1.0345 to $1.040 \mathrm{~g} / \mathrm{cm}^{3}$ and the viscosity at $4^{\circ} \mathrm{C}$ was 3.5 to $5.0 \mathrm{cP}$. Taking into account the individual differences in sedimentation rate between the semen of particular bulls (Kampschmidt, Mayer, Herman \& Dickerson, 1951), in every case a recipe was first worked out for a medium guaranteeing a uniform distribution of spermatozoa into particular fractions of the sedimenting suspension. 
Immediately after ejaculation, $4.5 \mathrm{ml}$ of semen was first mixed with an equal volume of the appropriate liquid medium at $37^{\circ} \mathrm{C}$ and then cooled in a water bath to approximately room temperature. This suspension was layered on a 32-cm liquid column at $2^{\circ}$ to $4^{\circ} \mathrm{C}$, filling a sedimentation burette. Then, at five intervals of $1 \mathrm{hr}$, six fractions of $5.5 \mathrm{ml}$ each were recovered from the column. The first four fractions differed in the length of time sedimented and the amount of sedimentation, but the last two fractions which were taken consecutively differed only in the amount of sedimentation. The aim in taking particular fractions at different times was to obtain a stronger differentiation of the average sedimentation rate of spermatozoa. The sterile precautions observed in the laboratory where the experiment was carried out may be considered as satisfactory in view of the very good insemination results obtained at the Centre.

The concentration and motility of the spermatozoa were estimated in each fraction, which was afterwards diluted in a $10 \%$ egg-yolk suspension in whole milk, with $0 \cdot 1 \mathrm{~g}$ of streptomycin and $100,000 \mathrm{i} . u$. penicillin $/ 100 \mathrm{ml}$ added to give a concentration of $\pm 30 \times 10^{6}$ regularly motile spermatozoa $/ \mathrm{ml}$. Aliquots of $1.2 \mathrm{ml}$ of the suspension of spermatozoa were used for inseminations.

Inseminations were carried out between September 1967 and March 1968 on individual, as well as collective, farms in the Cieszyn and Bielsko districts. The inseminators registered the sex of calves born without any knowledge of the aim of the experiment. Occasional inspections proved the reliability of their records.

Control tests consisted of insemination with unsedimented semen from the same bulls, 2 or 3 weeks before or after insemination with sedimented semen. The number of inseminations with control and sedimented semen was similar for each individual. At the time of insemination, the sedimented semen was 6 to $18 \mathrm{hr}$ older than the control semen.

The results shown in this work include both first $(75 \%)$ and repeated $(25 \%)$ inseminations, with the exception of calvings occurring more than 15 days after or, in the case of a repeat insemination, more than 15 days before the expected date of delivery. This precaution permitted the inclusion of the results of repeat inseminations.

The progeny of 2866 cows inseminated with sedimented semen and of 2171 cows inseminated with unsedimented semen were compared. The SR of calves born after insemination with Fractions I and II and III and VI of the sedimented semen was compared with the SR of calves in a control group inseminated with semen prepared in the routine way. A comparison was made between the progeny of all the sires together (Tables 1 and 2) and also between the progeny of each sire separately (Text-fig. 1).

The influence of the method of separation on the motility and biological effectiveness of the spermatozoa was also studied.

\section{RESULTS}

Effects of sedimentation on the motility of spermatozoa

Among the 162 samples resulting from fractionation of the semen, there were thirty-six where the motility of the spermatozoa was lowered and these 
were not used for insemination. The spermatozoa of some bulls seemed to be particularly susceptible to damage by the method used.

The non-return-to-service rate

This rate was lower after insemination with any of the fractions than after insemination with control semen (Table 1). It was lowest after insemination with Fractions II and IV.

The calving-to-service rate

Calving occurred after insemination with sedimented semen in $67.4 \%$ of inseminations. This percentage was lower $(7.6 \%)$ relative to control inseminations than the index of non-return-to-service rate $(3.6 \%)$. There were differences in the lowering of the calving-to-service rate actually observed, depending on the fraction of the spermatozoa used (Table 1), as well as differences in the lowering of the calving-to-service rate of individual sires (Text-fig. 1).

\section{Secondary sex ratio}

The following values were obtained:

after insemination with Fractions I and II

after insemination with Fractions III and IV

$111 \cdot 7$

after insemination with Fractions $V$ and VI

$114 \cdot 7$

after insemination with control semen

$116 \cdot 7$

A paradoxically high SR $(122 \cdot 1)$ was noted after insemination with Fraction III.

The number of females in the progeny born after insemination with Fractions I and II $(53.9 \%)$ was higher than in progeny born after control insemination $(46.8 \%$ ) by $15 \%$. No deviation in favour of the males was observed from insemination with the spermatozoa sedimenting at a slower rate.

The SR of the progeny of individual bulls naturally differs (Text-fig. 1) and it would not be suitable, therefore, to rely only on sums of progeny, as in previous works. In the present study, the SR of the progeny after insemination with the spermatozoa in Fractions I and II and Fractions III to VI was also compared with the SR of the progeny of unsedimented semen from each sire (Text-fig. 1). The preponderance of females after inseminations with the more rapidly sedimenting spermatozoa found in the total was also noted when the progeny was checked separately. Insemination of Fractions I and II from fifteen of the seventeen bulls resulted in a higher percentage of females than insemination with control semen and than insemination with the more slowly sedimenting fractions. Unfortunately, insemination with the more slowly sedimenting spermatozoa from only seven of those seventeen bulls resulted in a higher percentage of males compared with the results of insemination of control semen.

\section{DISCUSSION}

The SR of progeny born after insemination with the first two fractions of semen, which resulted in a statistically significant preponderance of females (Table 2) 


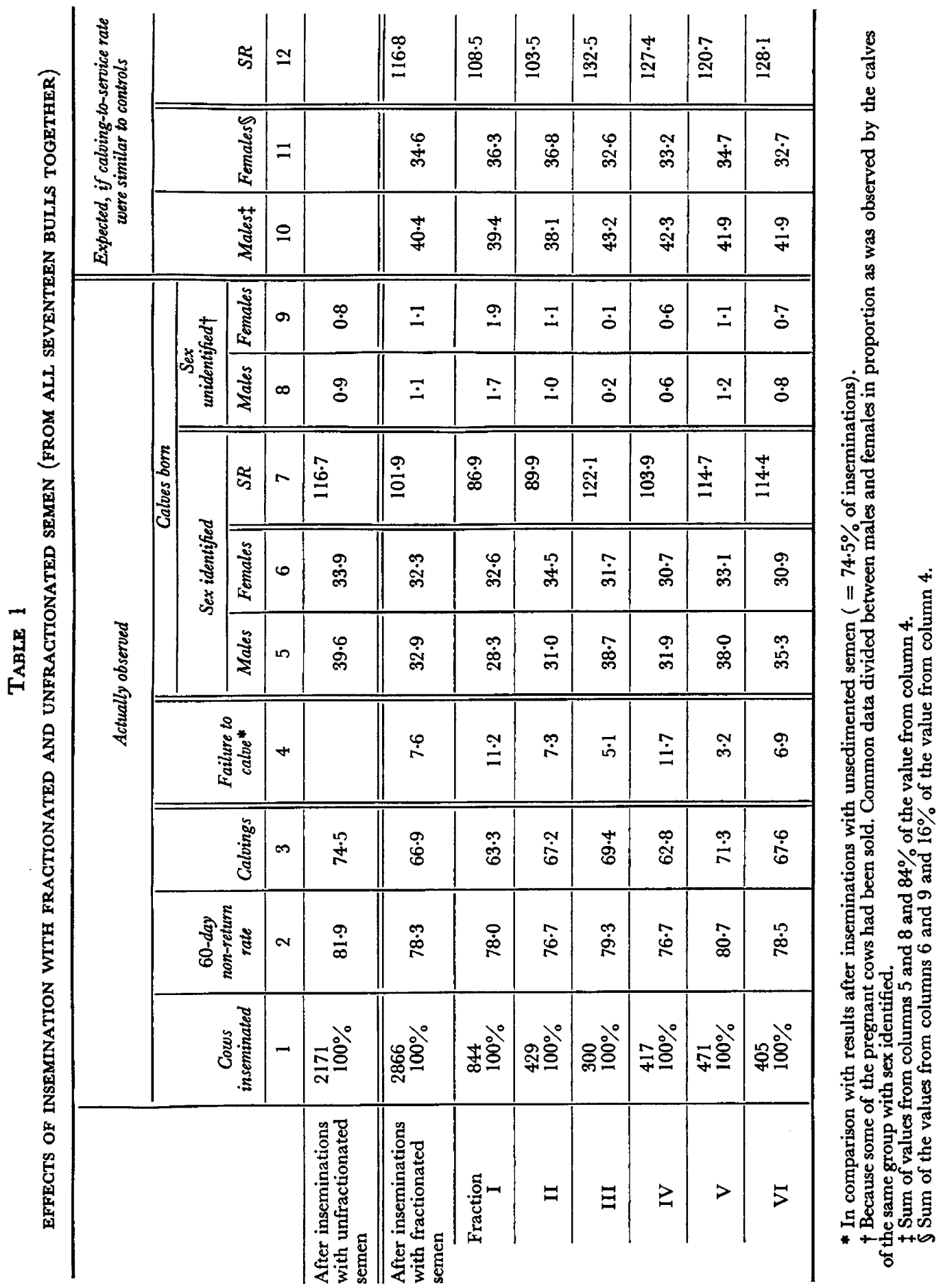




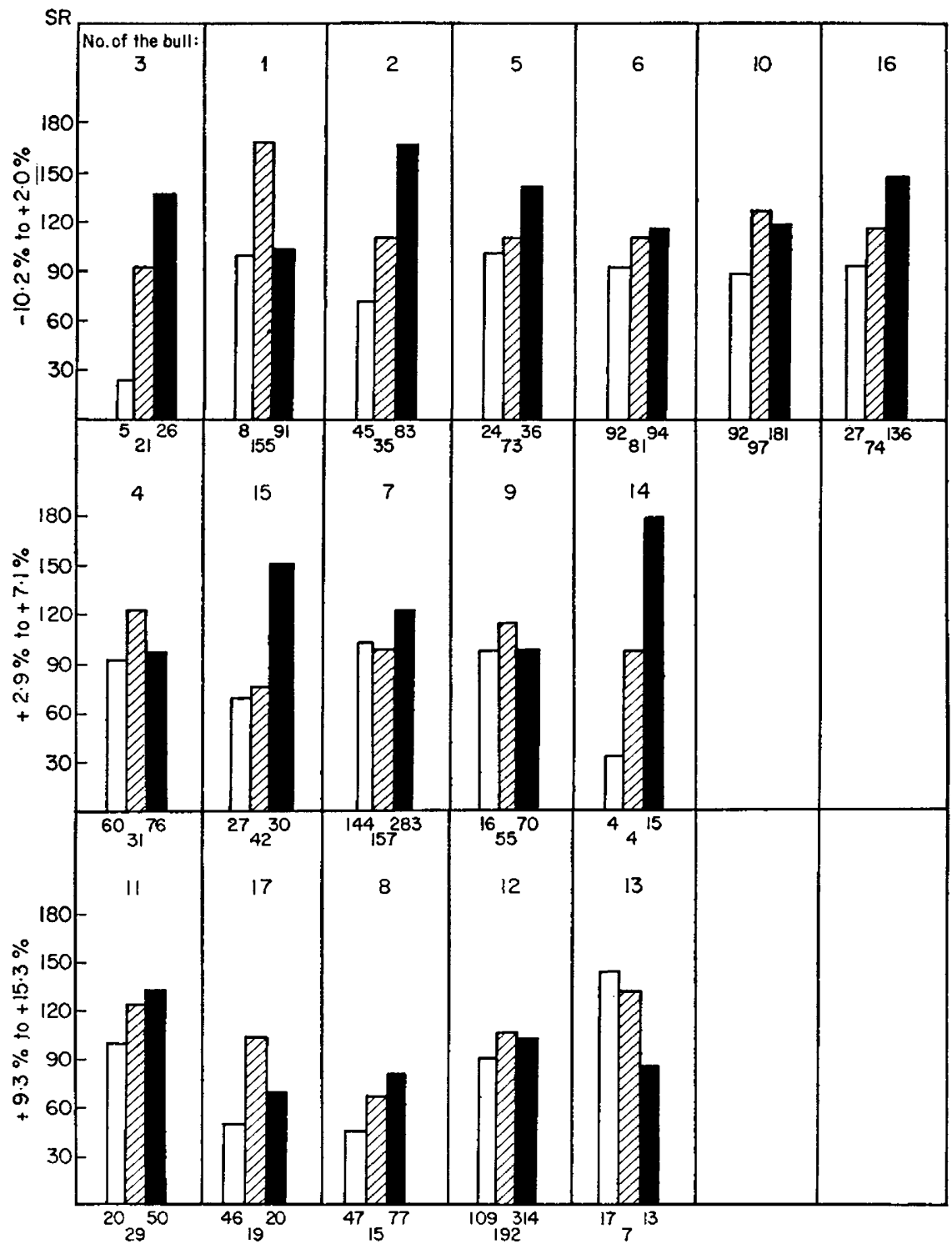

Texr-FIG. 1. Sex ratio: Open columns-after insemination with Fractions I and II; hatched columns-after insemination with Fractions III to VI; solid column-after insemination with unsedimented semen. Abscissa: The bulls are differentiated into three groups according to the increase in the frequency of abortion or failure to calve in cows caused by sedimentation of the semen used for insemination. Figures below the columns estimate the numbers of progeny. Ordinate: Failure to calve of cows inseminated with sedimented semen higher $(+)$ or lower $(-)$ in comparison with controls.

supported the basic hypothesis. By contrast, although the percentage of males after insemination of the four remaining fractions was higher than after insemination with the 'heavier' fractions, it was nevertheless lower than after the control inseminations.

The results obtained were worse than those obtained by Knaack (1968). 
They may have been affected during the sedimentation process by temperatures somewhat higher than $0^{\circ} \mathrm{C}$ which, according to Menger \& Knaack (1967), make the separation of $\mathrm{X}$ - and $\mathrm{Y}$-bearing spermatozoa impossible.

The zootechnical importance of the preponderance of females born after insemination with the 'heavier' spermatozoa is limited. The percentage of females was admittedly higher than that of males but, because of the lower calving-to-service rate, the absolute number of females born after 100 inseminations with sedimented semen was slightly higher than in controls only for Fraction II. The practical value of a method of sex regulation must, therefore, be estimated on the basis of the absolute number of progeny born with the defined sex and not on the basis of the SR.

Nevertheless, the results obtained here give rise to some interesting conclusions.

The calving-to-service-rate of cows bred with sedimented semen was, on average, lower by $7.6 \%$ than in the controls. It was due equally to a lower nonreturn-to-service rate $(3 \cdot 6 \%)$ as well as to a higher abortion-to-service rate

TABLE 2

THE DIFFERENCE IN SEX OF PROGENY ESTIMATED BY $\chi^{2}$ TEST

\begin{tabular}{|c|c|c|}
\hline & $\begin{array}{c}\text { After insemination with } \\
\text { Fractions III to VI } \\
\text { of semen }\left(571 \sigma^{\star} / 504 \text { \&ᄋ) }\right.\end{array}$ & $\begin{array}{c}\text { After insemination } \\
\text { with unsedimented } \\
\text { semen }(859 \circlearrowleft ð / 736 \text { ○ㅇ) }\end{array}$ \\
\hline $\begin{array}{l}\text { After insemination with Fractions } \\
\text { I and II of semen ( } 372 \delta \delta / 423 \text { 우) }\end{array}$ & $\begin{array}{c}P<0 \cdot 01 \\
\left(\chi^{2}=7 \cdot 31\right)\end{array}$ & $\begin{array}{c}P<0.01 \\
\left(\chi^{2}=10.56\right)\end{array}$ \\
\hline
\end{tabular}

$(4 \cdot 0 \%)$. The non-calving of cows which did not repeat oestrus may be due, both to some pathology of their generative organs simulating pregnancy by lack of oestrus, and to intra-uterine death of foetuses and/or abortion. On the supposition that the former cause was equally frequent in the investigated and the control material, it was assumed that the lower ratio of calving in cows which did not repeat oestrus was due to the latter cause, increased by the sedimentation of the semen used for insemination.

A comparison of the SR of all calves born after insemination with sedimented semen, independent of the fraction used, with the SR of the controls indicates that sedimentation generally worked to the disadvantage of male progeny. This is probably due to an increase in the number of abortions which, in humans, mainly affects male foetuses (Stevenson \& Bobrow, 1967). These facts led to a suggestion that the preponderance of females after insemination with Fractions I and II was only due to loss in the preponderance of male foetuses.

The assumption that all the foetuses lost because of the sedimentation of semen were male, still does not explain the difference between the SR following insemination with sedimented and control semen. It was inferred, therefore, that the method selectively eliminated male progeny at the stage of implantation of the ovum. The higher percentage of oestrus repeated within 60 days would be due to these increased implantation losses. It was calculated that the whole failure to calve divided among males and females in the proportion of $84 \%$ and $16 \%$ respectively and added in proportion to the natural calvings would make 
the SR after insemination with total sedimented and control semen similar (Table 1-expected SR). The difference in SR between the first two, and the four remaining, fractions is marked even after this re-adjustment. This led to the assumption that the method of separation of spermatozoa is effective and does influence the primary SR.

The bulls, whose progeny are shown in Text-fig. 1, have been divided into three groups according to the degree of abortion increase in those cows inseminated with the sedimented semen compared with the controls. It became evident that for each bull the relations between SR, depending on the type of semen used for insemination, were in some measure similar in each group of bulls. Except for one bull in the middle group (No. 9) and one bull in the lower group (No. 13), there was a preponderance of females in the progeny resulting from insemination of the first two fractions of sedimented semen compared with the controls. The fact that this was also shown by the data recorded for the upper group of bulls, whose semen was able to resist the damaging effects of the method, proves that the preponderance of females was not only caused by the increase in abortion in cows inseminated with sedimented semen.

It was noted that the resistance of the semen from individual bulls to the damaging influences inherent in this method of sedimentation varied. The resistance apparently corresponded to the calving-to-service rate of cows inseminated with the semen of these bulls in the routine way.

It may be noted that the SR after insemination of unsedimented semen of the bulls in the upper row of Text-fig. 1 is generally higher than that of the bulls in the lower one. The cumulative SR after insemination of the semen of the bulls in the upper row was $128.6(364 / 283)$, in the middle row $121.5(260 / 214)$ and in the lower row $98.3(235 / 239)$. This led to the supposition that the semen of those bulls which beget a prevalence of males is more resistant to the damaging effects of outside factors leading to abortion through the fault of the sire. The fact that too few inseminations were performed with the semen of some bulls only allowed a comparison between groups; the apparent correlation should be checked on a larger sample.

The probable relationship between the biological value of the spermatozoa (different numbers of non-return-to-service and calving-to-service rates of cows inseminated with spermatozoa from different fractions) and the characteristics of their sedimentation will be the subject of another investigation.

In spite of the assumption on which the sperm-separation method is based, the more rapid sedimentation of the spermatozoa with an $\mathrm{X}$ chromosome is not caused by their supposedly greater weight. This became evident by comparing the actual and the theoretical sedimentation rate calculated by Stokes's formula, the actual rate being markedly higher. Although Stokes's formula has been worked out for the sedimentation of spherical bodies, it may also apply to ellipsoidal ones (Bachman, 1950; Lamb, 1957). According to Stokes's formula, the sedimentation rate of the spermatozoa is

$$
\mathrm{V}=\frac{\left(\mathrm{d}-\mathrm{d}^{\prime}\right) \times \mathrm{m} \times \mathrm{g}}{3 \times \mathrm{d} \times \mathrm{S} \times \eta}
$$


where $d=$ density of spermatozoa. Opinions differ as to the average density of spermatozoa from 1.076 (Lavon, Volcani, Amir \& Danon, 1966) to 1.335 (Lindhal \& Kihlström, 1952). When the opinions about the real values of figures which are to be substituted in the formula differed from one another, we accepted those which overstated the final result. It was assumed, therefore, that $\mathrm{d}=1.335 \mathrm{~g} / \mathrm{cm}^{3}$.

$\mathrm{d}^{\prime}=$ the density of the sedimentation medium. It is assumed that $\mathrm{d}^{\prime}=$ $1 \cdot 035 \mathrm{~g} / \mathrm{cm}^{3}$.

$\mathrm{m}=$ the mass of the spermatozoa, equal to the product of the density and the volume of the spermatozoa. It is assumed that the volume $=23 \mu^{3}$ (Iversen, 1965); after multiplication, $\mathrm{m}=30 \cdot 7 \times 10^{-12} \mathrm{~g}$.

$\mathrm{g}=981 \mathrm{~cm} / \mathrm{s}^{2}$.

$\eta=$ the viscosity of the sedimentation media used. The lowest value was assumed, i.e. $3.5 \mathrm{cP}=0.035 \mathrm{~g} / \mathrm{cm} \times \mathrm{s}$.

$\mathrm{S}=$ the circumference of the spermatozoa. The circumference of the head at its widest point was assumed as the basis for calculation. The diameter of the head was accepted as $3.5 \mu$ and the average circumference as $8 \mu$. It is probable that a value of $\mathrm{S}$ higher than that of the circumference of the head alone causes the friction which delays the sedimentation of spermatozoa. That error, however, also increases the final value of $\mathrm{V}$.

The maximum average rate of sedimentation of one spermatozoon thus calculated ought to be $0.29 \mathrm{~cm} / \mathrm{hr}$. In reality, it was at least a hundred times higher.

The difference may only be explained on the assumption that the spermatozoa do not sediment separately but in agglomerations.

All the parameters of the cited formula, with the exception of the mass $\left(4 / 3 r^{3} \pi d\right)$, are unvarying in the discussed system, while it is possible that the radius of the settling bodies varies because of the cells' known ability to agglomerate. Indeed, the semen, if layered on transparent liquids (solutions of dextran, milk plasma and even the seminal plasma homogeneous for the semen), does not sediment uniformly, but forms drops or floccules (author's unpublished observations).

The seminal plasma appears to have considerable influence on the agglomeration of the sedimenting spermatozoa. Spermatozoa washed three times in $0.85 \%$ $\mathrm{NaCl}$ or in $5 \%$ glucose and re-suspended in the liquids used for washing, or washed in $0.85 \% \mathrm{NaCl}$ and re-suspended in the whey, sediment more slowly in the homogeneous seminal plasma than does the same concentration of spermatozoa in whole semen. As the sedimenting spermatozoa also agglomerate at room temperature, when their motility is not inhibited, the cause of their agglomeration does not lie in the ability of the cells to aggregate, as observed for sedimenting erythrocytes. The characteristics of sperm agglomeration need further investigation.

The fact that the re-suspended spermatozoa of the last fraction sedimented at a slower rate than the spermatozoa of the first fraction may indicate that these two populations of cells have distinct differences in their ability to agglomerate. This is probably greater in $\mathrm{X}$ - than in Y-bearing spermatozoa. Differences in ability to agglomerate may, in turn, depend on differences in the surface 
properties of the spermatozoa. The probability of the existence of such differences was pointed out by Shettles (1961) who demonstrated the greater ability of the supposedly X-bearing spermatozoa to adsorb anise oil balls on their surface.

The preponderance of females born after insemination with the more rapidly sedimenting spermatozoa indicates that it is worth trying to improve this method of sex regulation, although its practical value is unsatisfactory at present because of the rather lower calving-to-service rate. The probable difference in the surface properties of X-and Y-bearing spermatozoa may, it seems, be used as a basis for their recognition and separation.

\section{ACKNOWLEDGMENTS}

The work was supported by the Institute of Zootechny in Poland. Thanks are due to Mr Ing. Z. Karwat for his help in organization, and to Mr K. Sawicz and Mrs A. Żwak for their part in the performance of the investigation. The author acknowledges very affectionately Dr L. Pietrzak, Head of Państwowy Zakład Unasieniania Zwierzat w Drogomyslu, whose courtesy permitted the realization of this work.

\section{REFERENCES}

Andersen, H. \& Rottensten, K. (1962) Forsog med konskontrol pa kaniner. Aarsberentnig Inst. Sterilitersforskn. Kong. Vet-og Landbohojskole Kopenhagen, p. 125. Cited by Schilling (1966).

BaGhmann, D. (1950) Die Sedimentationswaage, ein neues schreibendes Gerät fur Feinheitsanalyse. Dechema-Monogr. 31, 23. Cited by Bhattacharya (1962).

Bedford, J. M. \& Bibeau, A. M. (1967) Failure of sperm sedimentation to influence the sex ratio of rabbits. F. Reprod. Fert. 14, 167.

Bhattacharya, B. C. (1958) Sex control in mammals. Z. Tierzücht. ZüchtBiol. 72, 250.

Bhattacharya, B. C. (1962) Die Verschiedene Sedimentationsgeschwindigkeit der X und Y-Spermien und die Erage der willkürlichen Geschlechtsbestimmung. Z. wiss. Zool. A, 166, 203.

Bhattacharaya, B. C., Bangham, A. D., CRo, R. J. \& Keynes, R. D. (1966) An attempt to predetermine the sex of calves by artificial insemination with spermatozoa separated by sedimentation. Nature, Lond. 21, 91.

IVERSEN, S. (1965) Volume of untreated and ultrasonically-treated bull, boar and human spermatozoa electronically determined. F. Reprod. Fert. 9, 197.

Kampschmidt, R. F., Mayer, D. T., Herman, H. A. \& Dickerson, G. E. (1951) Sedimentation of spermatozoa and settling of diluter solids and their effects upon survival of spermatozoa during storage. F. Dairy Sci. 34, 21.

KNAACK, J. (1968) Willkürliche Geschlechtbeeinflussung durch sedimentierte Rinderspermien (Ergebnisse eines Grossversuchs). Fortpfl. Zuchthyg. Haustierbesam. 4, 279.

LamB, H. (1957) Hydrodynamics, p. 614. Cambridge University Press. Cited by Bhattacharya (1962).

Lavon, U., Volcani, R., AmiR, D. \& Danon, D. (1966) The specific gravity of bull spermatozoa and seminal plasma. F. Reprod. Fert. 11, 447.

Lindahl, P. E. \& Kinlström, J. E. (1952) Alterations in specific gravity during the ripening of bull spermatozoa. F. Dairy Sci. 35, 293.

Menger, H. \& KnaAcK, J. (1967) Möglichkeiten für eine Trennung der X und Y tragenden Spermien. Wiss. Z. Karl-Marx-Univ. Lpz. 16, 275.

Schilirivg, E. (1965) Experimentalle Untersuchungen zur Geschlechtsbeeinflussung beim Rind. Naturwissenschaften, 52, 353.

Schiling, E. (1966) Trennung von Bullenspermien durch Sedimentation und Zentrifugation und das Geschlecht der geborenen Kälber. Z. Saügetierk. 31, 313.

Shettues, L. B. (1961) Differences in human spermatozoa. Fert. Steril. 12, 20.

Stevenson, A. G. \& Bobrow, M. (1967) Determinants of the sex proportions in man with consideration of the evidence concerning a contribution from X-linked mutations to intrauterine death. $\mathcal{F}$. med. Genet. 4, 190. 